\title{
Hemispheric lateralization and handedness correlation of human evoked "steady-state" responses to patterned visual stimuli
}

\author{
W. R. KLEMM, W. D. GIBBONS, R. G. ALLEN, and E. O. RICHEY \\ Laser Effects Branch, USAF School of Aerospace Medicine, Brooks Air Force Base, Texas 78235
}

\begin{abstract}
We studied "steady-state" visual evoked potentials (VEPs) in 10 adult males (5 of whom were left-handed), using an alternating vertical-bar-pattern monocular stimulus in which the bar positions reversed at rates of 6,11 , and $16 \mathrm{~Hz}$. VEPs from electrodes over each hemisphere and midline were computer-averaged over $2 \mathrm{~min}$ and the average then subjected to spectral (Fourier) analyses. The stimulus reversals were square-wave regulated, and all subjects responded with near sine-wave spectral components (fundamental and some harmonics) at the corresponding reversal frequencies. Each subject developed larger responses at one of the stimulus frequencies (usually $6 \mathrm{~Hz}$ ). Response magnitude at either the fundamental or harmonics of the stimulus frequency varied greatly across subjects. One of the specific hypotheses tested was that larger VEPs should develop after stimulation of the dominant eye; this could not be demonstrated. Two other hypotheses were verified: (1) VEPs should be lateralized and should correlate with handedness, and (2) some of the response received in a given hemisphere is physiologically relayed to the other hemisphere, and this occurs in both directions. Hemispheric lateralization occurred most clearly at each subject's optimum frequency. The "dominant" hemisphere for this kind of stimulus was always in the left hemisphere for the five right-handed subjects and in the right hemisphere for four of the left-handed subjects (the other left-hander had marked left-hemisphere dominance and also several right-handed behaviors).
\end{abstract}

Vision research and clinical laboratories are increasingly employing the use of patterned bar or checked stimuli in which the light and dark areas are reversed at a constant frequency (Regan, 1977). Such stimuli evoke conspicuous, so-called "steady state" visual evoked potentials (VEPs).

Pilot studies in this laboratory have been aimed at increasing the sensitivity of such methods by performing additional spectral (Fourier) analysis on the VEPs. These studies have disclosed a great deal of unexpected subject variability, and the research reported here reflects our efforts to identify some of the more likely variables that influence the power spectral density (PSD) values associated with the VEP.

One possible source of VEP variability is the difference among subjects in the "dominant" eye (usually the right eye in right-handed people), which dominates in sighting or tracking a target (Porac \& Coren, 1976). In general, the conventional light flash stimulation of the dominant eye can cause larger VEPs than those obtained with the nondominant eye, but these results have not always been obtained (reviewed by Perry \& Childers, 1972). Comparisons between contralateral and ipsilateral VEPs in response to nasal or temporal monocular stimulation have been contradictory.

W. R. Klemm's permanent address: Departments of Veterinary Anatomy and Veterinary Small Animal Medicine and Surgery, Texas A\&M University, College Station, Texas 77843.
HYPOTHESIS 1-Stimulation of the dominant eye should cause larger PSD value at the midline or a larger sum of the PSDs over both hemispheres than should nondominant eye stimulation.

Another source of variation is hemispheric localization in which one of the two hemispheres is functionally superior to the other (Harnard, Doty, Goldstein, Jaynes, \& Krauthamer, 1977; Sperry, 1974; Zaidel, 1978). Specifically, we would predict:

HYPOTHESIS 2-Hemispheric lateralization would be indicated by larger responses occurring in one hemisphere after whole-eye stimulation of either eye.

A third possible source of variation is the degree to which the sensory input that is received in one brain hemisphere is transferred to another, via interhemispheric connections (Berlucchi, 1974). Few direct connections exist between homologous regions of each hemisphere's occipital cortex (Wolff, 1958), but the visual cortex is anatomically contiguous with other cortical regions that do project transcallosally. In one study of a human with a transected optic chiasma but intact corpus callosum, virtually all of a flash-evoked VEP occurred ipsilaterally to monocular stimulation (Lehmann, Kavanagh, \& Fender, 1969) and was not clearly altered by simultaneous stimulation of the contralateral eye (Lehmann \& Fender, 1969). Despite these negative findings, our steady- 
state stimulus paradigm and the added analysis refinement of spectral analysis of the VEP make it important to test this issue in normal subjects.

HYPOTHESIS 3-Interhemispheric transfer of VEP would be indicated by significantly larger power values occurring in a hemisphere under stimulus conditions when direct anatomical pathways cannot be activated; specifically, this includes left-hemisphere responses to stimulation of nasal retina of the left eye and temporal retina of the right eye and right-hemisphere responses to stimulation of the nasal retina of the right eye and temporal retina of the left eye.

\section{METHOD}

\section{Subjects}

The subjects were all male members of the laboratory staff with normal visual acuity (or corrected by eyeglasses that were worn during the study). Five were left-handed and five righthanded. Four subjects had had limited previous exposure to the stimulus (one to four trials). A pointing test indicated that seven had dominant right eye and three had dominant left eye. Handedness was classified on the basis of the hand used in writing, eating, shaving, and throwing and batting a baseball.

\section{Visual Stimulation}

The stimulus was a pattern of vertical bars generated on a Hewlett-Packard display scope, Model 1311A, after a method developed by Technology Incorporated, San Antonio, Texas. Overall intensity of the screen was maintained at $3.6 \mathrm{fL}$ for all stimulus conditions. Size of the target was $7 \mathrm{deg}$, individual bars had a spatial frequency of 5 cycles $/ \mathrm{deg}$, and the contrast between light and dark bars was fixed at $50 \%$. The pattern was reversed at three different reversal rates-6, 11 , and $16 \mathrm{~Hz}$-thus producing an evoked potential at precisely this frequency. (Pattern reversal occurs when the light and dark bars are interchanged rhythmically, the second pattern being precisely the complement of the first; reversal frequency is two times the counterphase frequency) (Regan, 1977).

\section{Electroencephalogram Recording}

The evoked potentials were recorded with $\mathrm{Ag}-\mathrm{Ag} \mathrm{C1}$ pellet electrodes placed on the scalp over the visual cortex. Impedance checks (at $1 \mathrm{kHz}$ ) before and after testing verified that no electrode changed impedance by more than $5 \mathrm{k} \Omega$ and that impedance never exceeded $10 \mathrm{k} \Omega$. Three electrodes were used, one placed $2.5 \mathrm{~cm}$ above the inion on the midline and one on each hernisphere $2.5 \mathrm{~cm}$ lateral to the midline electrode. Monopolar recordings were made with the active electrodes being referenced to grounded electrodes on each earlobe. EEG signals were amplified with Grass P511J amplifiers (in a Model 78D recording system) and the signal was filtered with one-half amplitude cutoff points at 1 and $300 \mathrm{~Hz}$. The amplified responses were monitored with ink tracing on paper and recorded on FM tape (Ampex Model 2200). From the tape, signals were fed to a signal averager, Nuclear Data Model WD100, for on-line monitoring of the averaged signal and also to a Digital Equipment PDP-11/34 for on-line digitizing, averaging, and spectral analysis.

\section{Computer Analysis}

Spectral analysis was performed by the Fast Fourier Transform (FFT), using a rectangular window and no digital filtering. The FFT was calculated with $1-\mathrm{Hz}$ resolution from the averaged EEG signal (120 samples of $1 \mathrm{sec}$ duration each, synchronized to the stimulus frequency). The complete spectral width was $128 \mathrm{~Hz}$ (sample rate of $256 / \mathrm{sec}$ ), but, because no peaks appeared at the higher frequencies, computer plotting was over the range of 1 to $64 \mathrm{~Hz}$. Because VEP responses occurred precisely at the stimulus reversal frequency, we focused the analysis on the power at the fundamental frequency (reversal rate) and its harmonics; except when otherwise stated, power values for fundamental and harmonics were summed.

Prior to each experimental session, a $20-\mu \mathrm{V}$ square wave from a Grass square-wave calibrator was fed into the amplifiers, processed through the entire system, and analyzed to compare the power at the fundamental and harmonic frequencies to assure equalization of gain and spectral waveform of all recording channels.

Spontaneous alpha activity for each subject was characterized by computation of the power spectral density (PSD) over five successive 2-sec EEG samples from each hemisphere, beginning $30 \mathrm{sec}$ after each trial began. The frequency analysis band was $7-12 \mathrm{~Hz}$, with $1 / 2-\mathrm{Hz}$ resolution. The alpha frequency was determined from the frequency exhibiting the greatest power, summed over the $10 \mathrm{sec}$.

\section{Experimental Procedures}

The subject was seated in a darkened electrically shielded room $144 \mathrm{~cm}$ from the display screen. All recordings were done with monocular viewing of the screen. For whole-eye stimulation, records were initially obtained following stimulation of the dominant eye. Next, the temporal and nasal retina of the dominant eye were stimulated. Half-field stimulation was accomplished by occluding either the temporal or nasal portion of the subjects' spectacle lenses or by placing plano lenses in frames for those subjects not wearing corrective lenses. The occluders were positioned to bisect the subject's pupil.

The subject positioned his head in a head restraint and viewed a fixation point on the center of the screen. The subject was then tested to ensure that one-half of the visual field was occluded. The procedure was repeated for the nondominant eye.

Ocular dominance was determined by having the subject point at a distant target with both eyes open. Each eye was then occluded separately and the eye that was still aligned under monocular viewing was classified as the dominant eye (Walls, 1951). Results from this test were consistent with subject reports of which eye was routinely used as the sighting eye when both eyes could not be used.

\section{RESULTS}

\section{Overview of Subject Characteristics}

Handedness and ocular dominance. Handedness tended to correlate with ocular dominance (Table 1); this included the left-handed subject, H.E., who had several right-handed behaviors (shaving, throwing and batting a baseball, and eating). The three subjects that were exceptions in this regard were also exceptions in other significant regards. Subject K.S., for example, tried to be left-handed as a child, but parents and teachers trained him to be right-handed; he also shaves and throws a ball left-handedly. Subjects J.P. and C.J. both kick a football with their right feet, but J.P. throws a ball right-handedly and C.J. bats a baseball and eats right-handedly.

Spontaneous alpha activity. All subjects had a distinct alpha frequency that ranged from 7.5 to $11 \mathrm{~Hz}$ (Table 1), and seven subjects had clear hemispheric lateralization of the alpha that did not seem to correlate with handedness or ocular dominance. 
Table 1

Overall Characteristics of Subjects

\begin{tabular}{|c|c|c|c|c|c|c|c|c|c|c|c|}
\hline Subject & 1 & 2 & 3 & 4 & 5 & 6 & 7 & 8 & 9 & 10 & 11 \\
\hline W.G. & 41 & $\mathrm{R}$ & $\mathrm{R}$ & 11.0 & $\mathbf{R}$ & 5.9 & 24,009 & 6 & $\mathrm{~L}^{*} \dagger$ & 396 & 65 \\
\hline W.K. & 44 & $\mathbf{R}$ & $\mathrm{R}$ & 8.5 & & 2.6 & 43,790 & 6 & $\mathrm{~L} \dagger$ & 1,633 & 30 \\
\hline J.H. & 34 & $\mathrm{R}$ & $\mathbf{R}$ & 10.5 & $\mathbf{R}$ & 6.3 & 36,587 & 6 & $\mathrm{~L} \dagger$ & 172 & 11 \\
\hline R.A. & 56 & $\mathbf{R}$ & R & 10.5 & $\mathbf{L}$ & 28.9 & 8,121 & 6 & $\mathrm{~L} \dagger$ & 61 & 34 \\
\hline K.S. & 29 & $\mathbf{R}$ & $\mathrm{L}$ & $8.5,9.5$ & L & 13.3 & 23,210 & 16 & $\mathrm{~L} \dagger$ & 1,394 & 60 \\
\hline C.H. & 37 & L & L & 10.5 & L & 26.6 & 33,097 & 6 & $\mathrm{R} \dagger$ & 1,124 & 39 \\
\hline D.T. & 34 & L & L & 10.5 & & 1.5 & 39,906 & 11 & $\mathrm{R}$ & 265 & 28 \\
\hline H.E. & 42 & $\mathrm{~L}$ & $\mathrm{~L}$ & 11.0 & $\mathrm{R}$ & 29.9 & 61,606 & 11 & $\mathrm{R}$ & 290 & 38 \\
\hline J.P. & 33 & $\mathrm{~L}$ & $\mathrm{R}$ & 7.5 & & 2.1 & 16,720 & 6 & $\mathrm{~L}$ & 770 & 35 \\
\hline C.J. & 22 & $\mathrm{~L}$ & R & 11.0 & $\mathrm{R}$ & 24.0 & 19,021 & 11 & $\mathrm{R}$ & 667 & 10 \\
\hline
\end{tabular}

Note-Column $1=$ age. Column $2=$ handedness. Column $3=$ ocular dominance. Column $4=$ peak $\alpha$ frequency in Hertz. Column $5=$ locus of peak $\alpha$. Column $6=$ degree of $\alpha$ asymmetry in percent. Column $7=$ largest total $\alpha$ amplitude (7-11 Hz) (power spectral density value, expressed as digitized counts ${ }^{2}$; VEP value taken as sum of power at the stimulus frequency plus that at the harmonics). Column $8=$ best VEP frequency in Hertz. Column $9=$ locus of peak VEP. Column $10=$ peak VEP amplitude (power spectral density value, expressed as digitized counts ${ }^{2}$; VEP value taken as sum of power at the stimulus frequency plus that at the harmonics). Column $11=$ maximum harmonics at $6 \mathrm{~Hz}$ in percent (expressed as maximum percentage of the peak VEP power; 12-Hz and 18-Hz power summed). $\quad$ *The hemisphere having the second largest VEP response. †Midline.

The absolute amount of power in the peak alpha band varied enormously (7.5-fold) among subjects; none of the subjects had experienced formal meditation or biofeedback conditioning of alpha activity.

VEP characteristics. Each subject had a clearly larger response at one of the three stimulus frequencies, both in terms of peak power (Table 1) and of summed power (midline value plus value from both hemispheres) (Figure 1). The optimum frequency did not correlate with either peak alpha frequency or locus of power of peak alpha. The absolute magnitude varied over a 27 -fold range for peak power and over a 76-fold range for summed power and did not correlate with the optimum stimulus frequency, the peak alpha frequency, or the peak alpha amplitude.

The subjects also varied greatly in the degree to which the VEP contained significant power at harmonics of the fundamental frequencies (Table 1). The largest harmonic responses occurred with $6-\mathrm{Hz}$ stimulation, at which most subjects had spectral peaks at 12 and $18 \mathrm{~Hz}$. Although most subjects also had harmonic peaks in the response to $11-$ and $16-\mathrm{Hz}$ stimuli, the magnitude was usually small, being the greatest in Subject K.S. (peak PSD of 226 at $22 \mathrm{~Hz}$ and of 74 at $32 \mathrm{~Hz}$ ). There was a substantial positive correlation $(R=+.87$, correlation of ranks; $p<.001)$ at each subject's optimum frequency between the power (summed for both eyes over all electrodes) developed at the fundamental frequency when compared with the total harmonic power.

The peak power amplitudes generally correlated (contralaterally) with the handedness of the subjects; for example, responses were larger in the left hemisphere of right-handers (Table 2). The only exception was Subject J.P., whose right-handed tendencies have already been pointed out. The conditions that produced peak VEP amplitudes were usually very specific and, within any given subject, usually confined to only one combination of response site and the eye that was stimulated. Only a few subjects had relatively large responses under several such stimulusresponse site combinations.

All subjects were most responsive when either whole eye was stimulated, as opposed to temporal or nasal retinal stimulation alone. Magnitude of response did not appear to correlate in any clear or consistent way with the amount of desynchronization, synchronization, or alpha activity in the ongoing EEG during a given trial.

Subjective impressions. The subjects were asked to give opinions on the relative difficulty of "holding" the stimulus (preventing apparent lateral drift) and of sustaining the impression of the pattern reversal. All subjects reported that half-eye stimulation was more difficult than whole-eye stimulation and that temporal retinal (nasal-field) stimulation was generally considered easier to "hold" than nasal retinal stimulation; these impressions were usually verified by the power values of all the subjects. However, other subjective impressions were often very misleading.

\section{Tests of Hypotheses}

Ocular dominance. In nine subjects, VEPs in both hemispheres were larger after stimulation of one eye than after stimulation of the other. However, there was no correlation with whichever eye was dominant. Based on comparing the total response (power values for each hemisphere summed) produced at the optimum frequency for each subject, only the chance level of half of the subjects had greater responses when the dominant eye was stimulated. Indeed, three subjects (W.G., W.K., and C.J.) had substantially larger responses (1.4- to 1.8 -fold) to the optimum stimulus frequency when the nondominant 


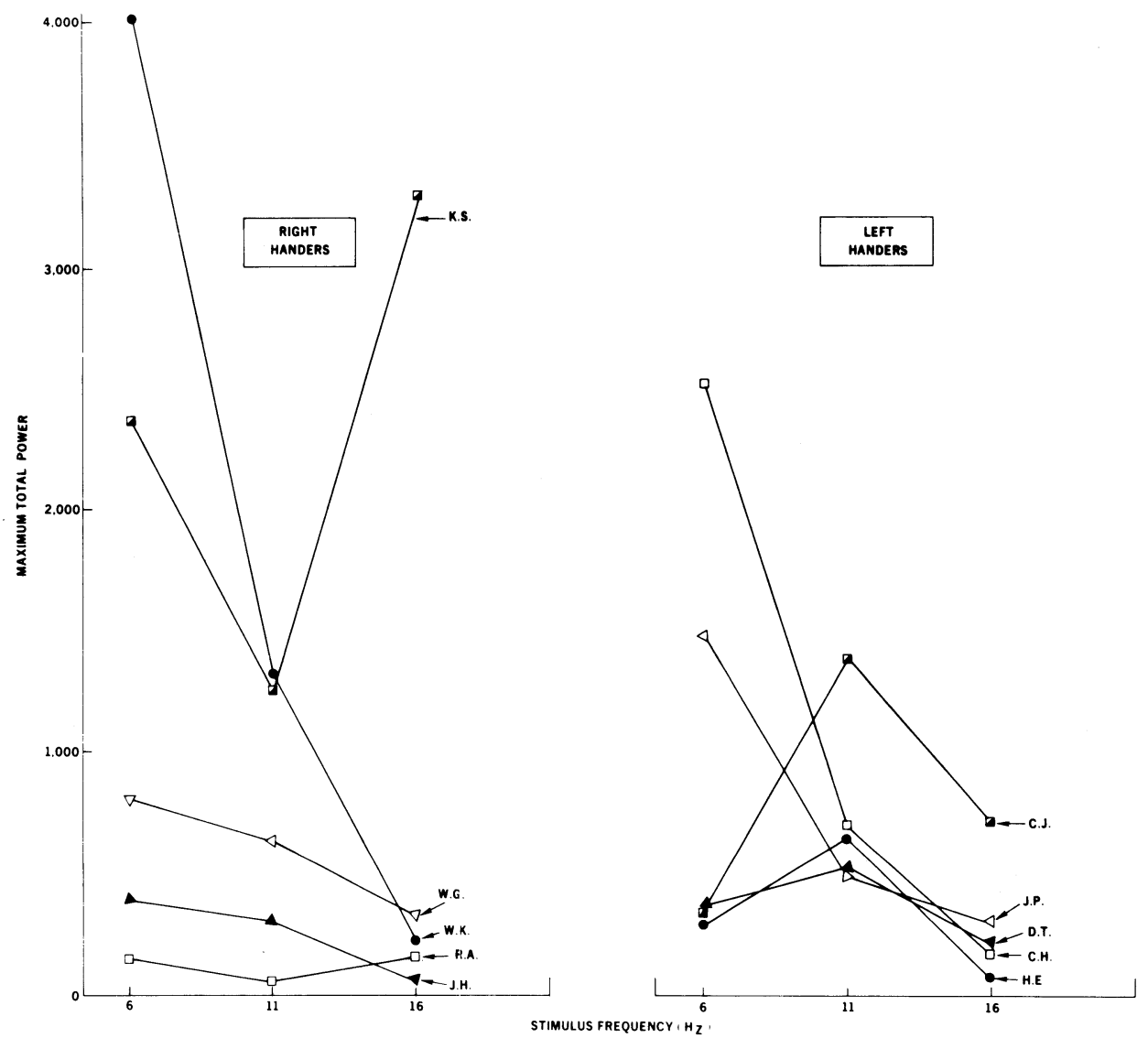

Figure 1. Plots of total power values at the EEG frequencies that corresponded to stimulus frequencies. Powers at these frequencies were summed over the three electrode sites for the eye that gave the larger responses, and powers measured at the harmonics of the fundamental were included in the total for the fundamental. Subjects generally had an optimum frequency at which the peak response was developed. For most subjects, the optimum frequency was $6 \mathrm{~Hz}$, but some subjects (see K.S. and C.J.) were conspicuously different.

eye was stimulated. Likewise, no significant differences were noted by comparing the summed potential amplitudes across all subjects at each of the stimulus frequencies. Furthermore, similar comparison of amplitudes at the midline electrode failed to disclose any differential effects.

Hemispheric lateralization and handedness correlation. Responses were larger over the expected dominant hemisphere than over the other (Figure 2), and the magnitude was greatest at each subject's optimum frequency ( $p<.001, t$ test) but was substantial at 6 and $11 \mathrm{~Hz}(\mathrm{p}<.02)$ (Figure 3). The failure to observe strong lateralization tendencies at $16 \mathrm{~Hz}$ was largely due to the small response of most subjects at this frequency. All three subjects who developed large responses at $16 \mathrm{~Hz}$ also had strong lateralization tendencies in the expected hemisphere at $16-\mathrm{Hz}$ stimulation of either eye (percentage difference between hemispheres, summed for both eyes, was $44 \%$ for K.S., $22 \%$ for D.T., and $52 \%$ for C.J.).

Right-handers developed larger responses over the left hemisphere, and left-handers, except for J.P., developed larger responses over the right hemisphere (omission of J.P.'s data does not change the statistical significance). Subject J.P. appears to be left-hemisphere dominant, because his best frequency left-hemispheric response was five times as large as his right-side responses. Individually, the smallest difference between hemispheres occurred in Subject R.A., who also had the smallest responses in general.

A quite unexpected correlation was noted that was unique to the power at the harmonic frequencies of the stimulus frequency. The peak total harmonic power for each subject, calculated in terms of the percentage of peak fundamental frequency power, occurred on the left side in all right-handers and in four of the five left-handers (Figure 4).

Interhemispheric transfer. The results clearly indicate that a substantial amount of the input received in one hemisphere is relayed in both directions from stimulation of either eye. All subjects revealed evidence of such transfer under several stimulus conditions (Figure 5). Response magnitude varied greatly with stimulus frequency, and the extent of apparent trans- 
Table 2

Hemispheric Lateralization and Handedness Correlation

\begin{tabular}{|c|c|c|c|c|}
\hline & \multirow{2}{*}{$\begin{array}{c}\text { Each Subject's } \\
\text { Optimum } \\
\text { Frequency }\end{array}$} & \multicolumn{3}{|c|}{$\begin{array}{c}\text { Stimulus Frequency } \\
\text { (in Hertz) }\end{array}$} \\
\hline & & 6 & 11 & 16 \\
\hline & \multicolumn{4}{|c|}{ Hemispheric Lateralization } \\
\hline \multicolumn{5}{|l|}{ Difference* } \\
\hline Mean & 47.5 & 35.1 & 28.1 & 17.9 \\
\hline $\mathrm{SE}$ & 5.9 & 5.5 & 5.8 & 8.0 \\
\hline Response Side** & $18 / 2$ & $17 / 3$ & $17 / 3$ & $9 / 11$ \\
\hline \multirow[t]{2}{*}{ Chi-Square $p$} & .01 & .05 & .05 & \\
\hline & \multicolumn{4}{|c|}{ Handedness Correlation } \\
\hline \multicolumn{5}{|l|}{ Difference $\dagger$} \\
\hline Mean & 42.7 & 26.3 & 27.0 & 4.4 \\
\hline $\mathrm{SE}$ & 6.7 & 6.3 & 6.8 & 6.9 \\
\hline Response Side $\nmid \dagger$ & $16 / 2$ & $15 / 3$ & $16 / 2$ & $8 / 10$ \\
\hline Chi-Square $p$ & .05 & .05 & .05 & \\
\hline
\end{tabular}

Note-For each subject, the VEP amplitude over each hemisphere was normalized relative to the subject's peak power, and the difference between hemispheres was determined by subtraction. Data were averaged over stimulation of both eyes. For the handedness correlation, J.P.'s data were omitted because he seemed to be a left-hander with left-hemispheric dominance. *Difference (in percent) between hemispheres. $\quad * *$ Number of times the response was greater on the expected/nonexpected side. tDifference (in percent) between assumed dominant side and nondominant side. TNumber of times the response was greater on the expected dominant/nondominant side.

fer did not necessarily correlate with stimulation at the most effective frequency.

\section{DISCUSSION}

\section{Hypothesis Testing}

Under no conditions was there any clear evidence for a role of ocular dominance.

Hemispheric lateralization was quite conspicuous, and clearly correlated with handedness. The subjects developed larger responses to whole-eye stimulation in the presumed dominant hemisphere. The only possible exception was Subject J.P., but he probably has a left-dominant hemisphere, because of his righthanded behaviors and his larger responses in the left hemisphere (Table 1). Note that the expected dominance effect was still evident in those subjects whose handedness was not absolute (K.S., H.E., and C.J.).

Finally, the results are consistent with the hypothesis that the response to sensory input in one hemisphere is transferred to the other side. Some of the represented response could have been due to ocular alignment errors; but the rather large degree of transfer and consistency across subjects and stimulus conditions makes it unlikely that error accounts for all of the responses. The physiological transfer of evoked responses may also have contributed to the large size of the midline VER (see below).

\section{Clinical Significance}

The most obvious conclusion seems to be that clinically normal subjects vary considerably in their responses to this kind of visual stimulation. Thus, the clinical utility of such methods would be greatest when the normal responsiveness of a given patient is known or when changes in VEP can be monitored over time.

Some of the more relevant observations include: (1) For monocular stimulation, the choice of eye seems relatively unimportant, (2) the largest responses should be expected to occur on the midline or over the hemisphere that is contralateral to the dominant hand, (3) amplitude of response will vary somewhat unpredictably with stimulus frequency, and (4) exceptionally large or exceptionally small VERs do not necessarily indicate clinical abnormality.

Also, these data suggest the possibility that steady state VEPs may permit one to determine objectively and noninvasively the locus of speech dominance, although this remains to be tested rigorously. Davis and Wada (1977) recently claimed that spectral analysis of averaged flash-evoked VEPs (and also click-evoked AEPs) could be used to identify the locus of speech dominance. They reported that the speech hemisphere (verified by the intracarotid barbiturate test) developed less coherence between the VEPs at occipital and temporal loci than did the VEPs over the other hemisphere.

\section{Neurophysiological Significance}

Individual differences in alpha frequency and the alpha symmetry have been reported by many others, but our results are not consistent with the recent report that right-handers have more alpha (percentage time that alpha is present) over the right hemisphere (Hirshkowitz, Earle, \& Paley, 1978). Perhaps total alpha power and percentage incidence are not always correlated.

The stimulus closest to normal alpha frequency was $11 \mathrm{~Hz}$, and in most subjects the largest VEPs were developed after $6-$ or $16-\mathrm{Hz}$ stimuli. Thus, the VEPs seem to be true physiological evoked responses rather than a reflection of some entrainment of endogenous alpha. Recall, also, that peak alpha and peak VEP did not correlate across subjects.

The variability among subjects in the VEP was quite marked. Perhaps the differences in maximum power and optimal frequency, and those relating to harmonic frequency responsiveness, relate to differences in attentiveness, intelligence, personality, special talents, etc.

The sinusoidal nature of the VEP indicates that the brain seems to act as a low-pass filter of higher frequency components of a square-wave input. Those subjects who responded well at the first harmonic presumably came closer to registering the true nature 

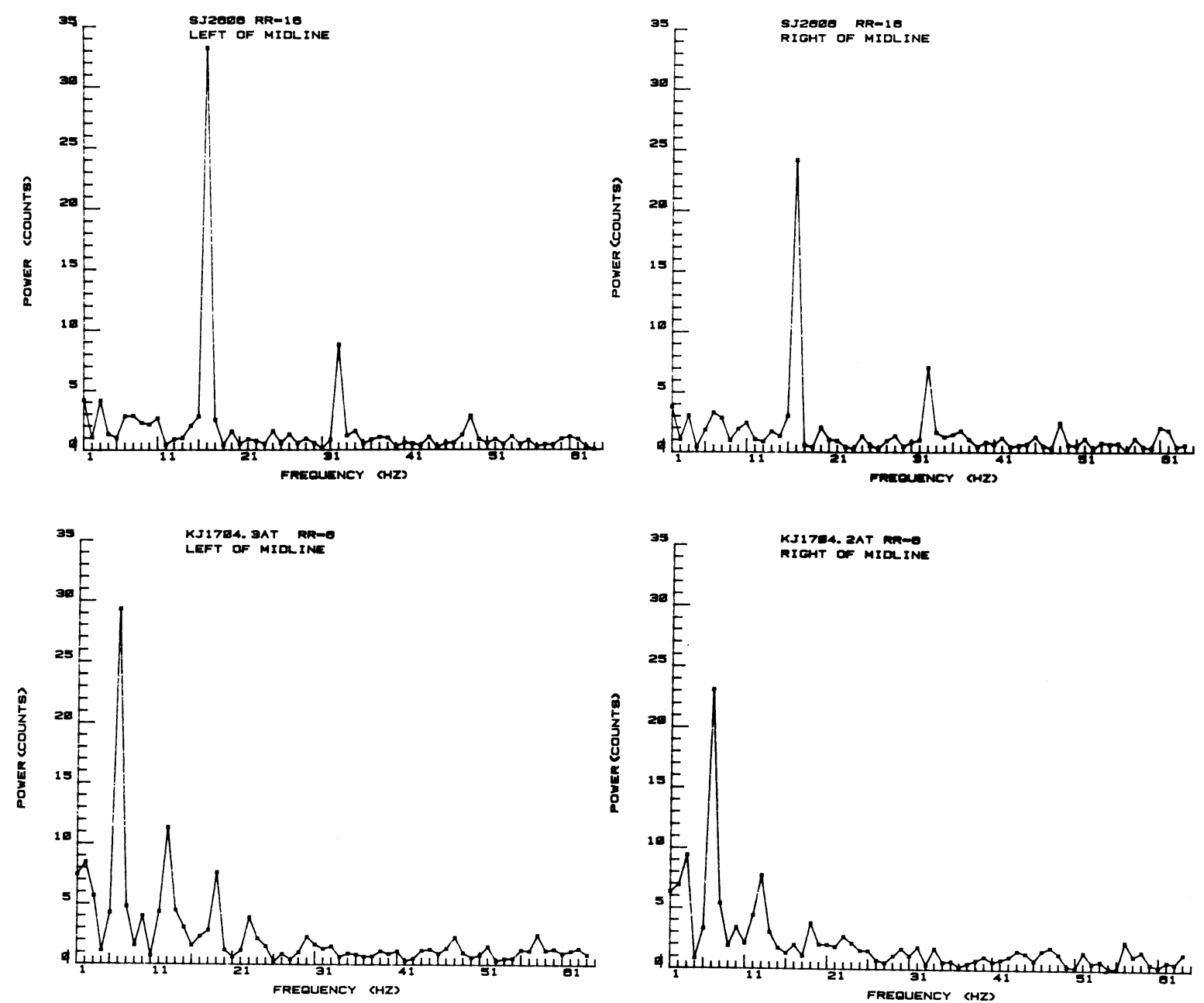

Figure 2. Spectra from two right-handed subjects illustrating hemispheric lateralization at each subject's optimal stimulus frequency (right-eye stimulation). Above, K.S. at $16 \mathrm{~Hz}$; below, W.K. at $6 \mathrm{~Hz}$. Note absence of significant power at frequencies other than the stimulus frequency and its harmonics and that lateralization occurs at the fundamental frequency and its harmonics.

of the stimulus; they also developed much power at the fundamental frequency. However, all subjects had significant power at the second harmonic (of $6 \mathrm{~Hz}$, up to $52 \%$ of peak power), indicating that the response was truly sinusoidal (square waves have odd-numbered harmonics).

Most previous research indicates that ocular dominance is most conspicuously a motoric phenomenon (reviewed by Porac \& Coren, 1976), and that is consistent with our findings. Note also that the methods we employed may be more sensitive than the more common analytical approaches of either averaging or spectral analysis (Regan, 1977).

Our demonstration of lateralization and handedness correlation of the VEP may surprise some investigators, because it is a common belief (Creel, O'Donnell, \& Witkop, 1978) that monocularly evoked VEPs to unpatterned stimuli in normal humans show little asymmetry. In reviewing the reports of such studies, Butler and Glass (1976) concluded that unstructured visual stimuli do not cause VEP asymmetries in right-handed males. There are reports, however, that lateralization can occur, both for unpatterned flash (Culver, Tanley, \& Eason, 1970; Dustman, Schenkenberg, Lewis, \& Beck, 1977; Eason, Groves, \& Bonelli, 1967; Gott \& Boyarsky, 1972) and rhythmic (Crowell, Kapuniai, \& Garbanati, 1977) stimuli.

Psychophysiological studies support the hypothesis that visual input is lateralized and correlated with handedness (reviewed by Hardyck \& Petrinovich, 1977). The reviewers suggest that lateralization of visual function is organized along a continuum of handedness.

We suggest that such simplifications may not be appropriate for physiological measures involving the kind of stimuli we employed, which had not only a spatial character, but also a temporal element that 


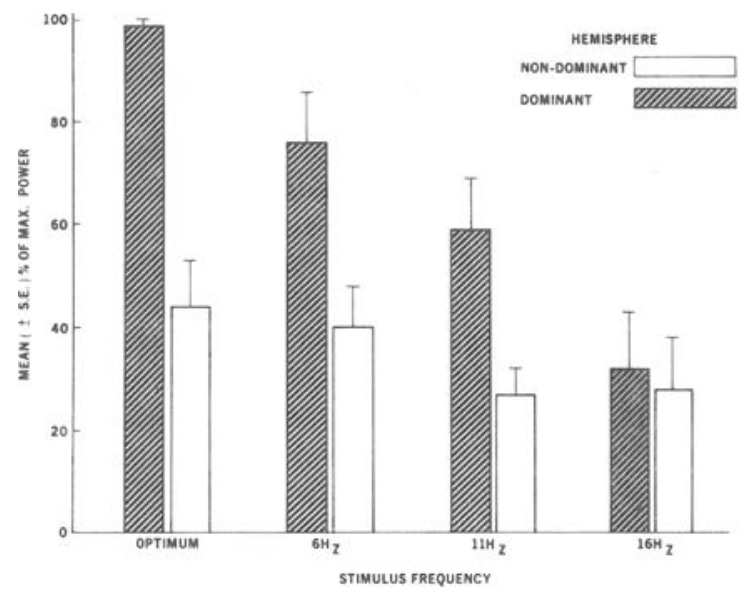

Figure 3. Mean amplitude differences for all subjects in the responses between the two cerebral hemispheres. The presumed dominant hemisphere is the one contralateral to the dominant hand (except for data of Subject J.P., the left-hander with clear left-hemispheric dominance for this stimulus). Data shown are based on the sum of the powers (at fundamental plus harmonic frequencies) evoked by stimulation of both eyes at each subject's optimum frequency and separately at the three frequencies; the sum is then normalized relative to the peak amplitude evoked for each subject.

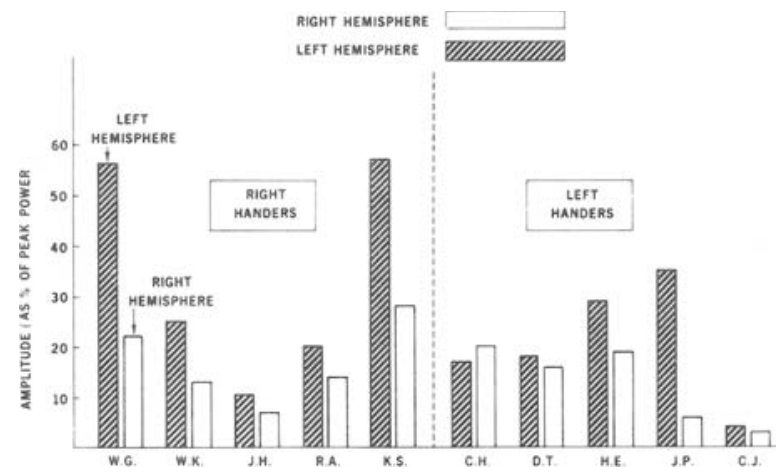

Figure 4. Power data of harmonics to the 6-Hz stimulation of each subject. Shown are the peak power values for each hemisphere, expressed as the percentage of the peak power value developed by each given subject. Nine of the subjects reveal a distinct preferential lateralization of harmonic response on the left side, occurring even in four of the left-handed subjects.

may well require a qualitatively different analysis mode of brain operation. This point could relate to our observation that lateralization could occur in the speech, but not the spatial, hemisphere. Which hemisphere is dominant for a visual spatial stimulus may depend on several factors; the one discussed in the literature is the degree to which subconscious verbalization occurs for the stimulus (Berlucchi, 1974).

In a study of right-handed humans, Fontenot (1973) demonstrated that some nonverbal stimuli were perceived best from the left visual field (right hemisphere), but only when the stimuli were complex geometric drawings that were linguistically poorly "codable" (describable). Perception of simple line orientation (White, 1971) or rectangle orientation (Umiltá, Rizzolatti, Marzi, Zamboni, Franzini, Carmarda, \& Berlucchi, 1974) was accomplished best in the left hemisphere of right-handers. More recently, the foregoing issue has been tested explicitly: Comparison of simple vs. complex geometrical stimuli revealed that right-handers had faster reaction times for recognition of simple stimuli presented to the right visual field and of complex stimuli presented to the left visual field (Umiltá, Barnara, \& Simion, 1978).

The lateralization of harmonics to the left hemisphere, even in left-handers, raises intriguing questions about the role of speech in processing such stimuli. The key, nonspatial aspect of our stimulus seems to have been the rhythmic reversal rate, and the neural response, or "following," may well have required the kind of precision neural operations that are more characteristic of the speech-dominant hemisphere. There is other evidence that the speech hemisphere is more efficient in timing perception (Carmon \& Nachshon, 1971; Swisher \& Hirsch, 1972). Particularly pertinent is Robinson and Solomon's (1974) report that auditory stimuli with temporal patterns of puretone sound (rhythms) containing no phonetic information were perceived best by the speech-dominant hemisphere of right-handed subjects, who were stimulated with 30 dichotic pairs of rhythms in each ear.

Finally, our results indicating transcallosal transfer seem significant because the human visual cortices are not known to have direct anatomical projections through the callosum (although in cats there apparently are cortical cells in both hemispheres that receive stimuli from the vertical midline of the visual field; Hubel \& Wiesel, 1967). The discrepancy between



Figure 5. Power data of fundamental plus harmonics for halffield retinal stimulation under conditions that would be expected to reflect interhemispheric transfer of visual evoked responses (i.e., left-hemispheric responses to stimulation of left nasal retina or right temporal retina, etc.). Individual subject data are arranged in the same left-to-right order as found in Table 1. Responses are expressed as the percentage of the peak power produced by halffield stimulation of each subject at his optimum frequency. The data from all subjects are indicative of a variable degree of interhemispheric transfer under most of the possible conditions. 
our results and those of Lehman et al. (1969) may be due to the differing methods. There are other published reports that do support the hypothesis of transcallosal transfer (Butler \& Glass, 1976; Donker, Nijo, van Leeuwen, \& Wieneke, 1978; Shagass, Amadeo, \& Roemer, 1976).

\section{REFERENCES}

Berlucchi, G. Cerebral dominance and interhemispheric communication in normal man. In F. O. Schmitt \& F. G. Worden (Eds.), Neurosciences. Cambridge, Mass: M.I.T. Press, 1974.

Butler, S. R., \& Glass, A. EEG correlates of cerebral dominance. In A. H. Riesin \& R. F. Thompson (Eds.), Advances in psychobiology. New York: Wiley, 1976.

Carmon, A., \& Nachson, I. Effect of unilateral brain damage on perception of temporal order. Cortex, 1971, 7, 410-418.

Creel, D., O'Donnell, F. E., JR., \& Witkop, C. J., JR. Visual system anomalies in human ocular albinos. Science, 1978, 201, 931-933.

Crowell, D. H., Kapuniai, L. E., \& Garbanati, J. A. Hemispheric differences in the rhythmic responses to photic stimulation in human infants. In J. E. Desmedt (Ed.), Visual evoked potentials in man: New developments. Oxford: Clarendon, 1977.

Culver, C. M., Tanley, J. C., \& Eason, R. G. Evoked cortical potentials: Relation to hand dominance and eye dominance. Perceptual and Motor Skills, 1970, 30, 407-414.

DAvis, A. E., \& WADA, J. A. Lateralization of speech dominance by spectral analysis of evoked potentials. Journal of Neurology, Neurosurgery and Psychiatry, 1977, 40, 1-4.

Donker, D. N. J., Nuio, L. S., van Leeuwen, W., \& Wieneke, G. Interhemispheric relationships of responses to sine wave modulated light in normal subjects and patients. Electroencephalography and Clinical Neurophysiology, 1978, 44, 479-489.

Dustman, R. E., Schenkenberg, T., Lewis, E. G., \& Beck, E. C. The cerebral evoked potential; life span changes and twin studies. In J. E. Desmedt (Ed.), Visual evoked potentials in man: New developments. Oxford: Clarendon Press, 1977.

Eason, R. G., Groves, P., \& Bonelli, L. Differences in occipital evoked potentials recorded simultaneously from both cerebral hemispheres in man. Proceedings 75th Annual Convention of the American Psychological Association, 1967, 2, 95-96.

Fontenot, D. J. Visual field differences in the recognition of verbal and nonverbal stimuli in man. Journal of Comparative and Physiological Psychology, 1973, 85, 564-569.

GotT, P. S., \& Boyarsky, L. L. The relation of cerebral dominance and handedness to visual evoked potentials. Journal of Neurobiology, 1972, 3, 65-77.

Hardyck, C., \& Petrinovich, L. F. Left handedness. Psychological Bulletin, 1977, 84, 385-404.

Harnard, S., Doty, R. W., Goldstein, L., Jaynes, J., \& KraUthame R, G. Lateralization in the nervous system. New York: Academic Press, 1977.
Hirshkowitz, M., Earle, J., \& Paley, B. EEG alpha asymmetry in musicians and nonmusicians: A study of hemispheric specialization. Neuropsychologia, 1978, 16, 125-128.

Hubel, D. H., \& Wiesel, T. N. Cortical and callosal connections concerned with the vertical meridian of visual field in the cat. Journal of Neurophysiology, 1967, 30, 1561-1573.

Lehmann, D., \& Fender, D. H. Averaged visual evoked potentials in humans: Mechanism of dichoptic interaction studies in a subject with a split chiasma. Electroencephalography and Clinical Neurophysiology, 1969, 27, 142-145.

Lehmann, D., Kavanagh, R. N., \& Fender, D. H. Field studies of averaged visually evoked EEG potentials in a patient with a split chiasm. Electroencephalography and Clinical Neurophysiology, 1969, 26, 193-199.

Perry, N. W., \& Childers, D. Monocular contribution to binocular vision in normals and amblyopes. In G. B. Arden (Ed.), The visual system: Neurophysiology, biophysics and their clinical applications. New York: Plenum Press, 1972.

Porac, C., \& Coren, S. The dominant eye. Psychological Bulletin, 1976, 83, 880-897.

REGAN, D. Steady-state evoked potentials. Journal of the Optical Society of America, 1977, 67, 1475-1489.

Robinson, G. M., \& Solomon, D. J. Rhythm is processed by the speech hemisphere. Journal of Experimental Psychology, 1974, 102, 508-511.

Shagass, C., Amadeo, M., \& Roemer, R. A. Spatial distribution of potentials evoked by half-field pattern-reversal and pattern-onset stimuli. Electroencephalography and Clinical Neurophysiology, 1976, 41, 609-622.

SPERRY, R. W. Lateral specialization in the surgically separated hemisphere. In F. O. Schmitt \& F. G. Worden (Eds.), Neurosciences. Cambridge, Mass: M.I.T. Press, 1974.

Swisher, L., \& Hirsch, I. J. Brain damage and the ordering of two temporally successive stimuli. Neuropsychologia, 1972, 10, 137-152.

Umiltá, C., Rizzolatti, G., Marzi, C. A., Zamboni, G., Franzini, C., Camarda, R., \& Berlucchi, G. Hemispheric differences in the discrimination of line orientation. Neuropsychologia, 1974, 12, 165-174.

Umiltá, C., Barnara, S., \& Simion, F. Laterality effects for simple and complex geometrical figures, and nonsense patterns. Neuropsychologia, 1978, 16, 43-49.

WAlls, G. L. A theory of ocular dominance. Archives of Ophthalmology, 1951, 45, 387-412.

White, M. J. Visual hemifield differences in the perception of letter and contour orientation. Canadian Journal of Psychology, 1971, 25, 207-212.

WolfF, E. The anatomy of the eye and orbit. New York: McGraw-Hill, 1958.

ZAIDEL, E. Concepts of cerebral dominance in the split brain. In P. Boser \& A. Rougeul-Buser (Eds.), Cerebral correlates of conscious experience. Amsterdam: Elsevier, 1978.

(Received for publication August 13, 1979; revision accepted February 22, 1980.) 